\section{An inguinal hernia or a greater saphenous vein aneurysm? A case report}

\author{
Seyhan Yılmaz, ${ }^{1}$ Sabür Zengin, ${ }^{2}$ \\ Fatma Gürgen, ${ }^{3}$ Feryaz Kızıltan ${ }^{4}$
}

${ }^{1}$ Department of CardioVascular Surgery, Özel Giresun ADA Hospital, Giresun; ${ }^{2}$ Department of CardioVascular Surgery, Kırıkkale Yüksek İhtisas Hospital, Kurıkkale; ${ }^{3}$ Department of Radiology, Özel Giresun ADA Hospital, Giresun; ${ }^{4}$ Department of CardioVascular Surgery, Okmeydanı Education and Research Hospital, Istanbul, Turkey

\begin{abstract}
Superficial venous aneurysms, which are mostly asymptomatic and detected when patients were referred to for the treatment or evaluation of a femoral or inguinal hernia or soft tissue masses, are associated with a risk of developing pulmonary embolism. We aimed to present a case of a greater saphenous vein aneurysm of which its misdiagnosis possesses morbidity risk and confused with inguinal hernia. A 45year-old female patient admitted to our clinic with swelling and pain in her right groin that had been present for about three years. The patient was also treated with inguinal hernia repair once due to her related complaints. A venous color doppler ultrasound was performed for differential diagnosis and a 70x31-mm sized fusiform proximal greater saphenous vein aneurysm and a grade-4 pathologic reflux in the right saphenofemoral junction was observed in the ultrasonographic examination. As a result, the swelling detected in the inguinal region should be evaluated in terms of possible superficial venous aneurysm, which may cause thromboembolism and ruptures, and this condition, which is frequently confused with inguinal hernia, should be taken into consideration and taken under operation as soon as possible in case of its presence.
\end{abstract}

\section{Introduction}

The aneurysm of the greater saphenous vein is even rarer in primary venous aneurysms which is a rare clinical case that may develop due to trauma, inflammation, and degenerative changes, often associated with congenital or connective tissue disorders too. ${ }^{1,2}$ Superficial venous aneurysms, which are mostly asymptomatic and detect- ed when patients were referred to for the treatment or evaluation of a femoral or inguinal hernia or soft tissue masses of the lower extremities, are associated with a risk of developing pulmonary embolism..$^{2-4}$ In our case report, we aimed to present a case of a greater saphenous vein aneurysm of which its misdiagnosis possesses morbidity risk and confused with inguinal hernia.

\section{Case Report}

A 45-year-old female patient admitted to our clinic with swelling and pain in her right groin that had been present for about three years. The patient was followed-up with inguinal hernia diagnosis for the last three years and had never been consulted to the vascular surgery unit before. The patient was also treated with inguinal hernia repair once (six months before) due to her related complaints. She was referred to us since her preoperative complaints persisted. The patient did not have any details like trauma and inflamatuary diseases other than the presence of accessory kidney in her history. Physical examination revealed no differences in diameters and edema in the lower extremities. The patient's vital signs were stable, and her electrocardiography and blood tests were normal. In the medialproximally section of the right inguinal region, a non-pulsatile swelling was found about $3-4 \mathrm{~cm}$ in diameter, prominent when the patient was standing and straining, and recessed and easily compressible when the patient was in supine position. An incision scar of inguinal hernia operation was observed in the right inguinal region, approximately $2-3 \mathrm{~cm}$ proximal to the inguinal fold. A venous color doppler ultrasound was performed for differential diagnosis and a 70x31-mm sized fusiform proximal greater saphenous vein aneurysm and a grade- 4 pathologic reflux in the right saphenofemoral junction was observed in ultrasonographic examination. Slow flow was observed in the aneurysm sac; however, no thrombosis was observed (Figure 1).

Although the patient was offered an operation for an aneurysm repair because of the pain and swelling complaints and the risk of thromboembolism, she refused the operation since she was going to return to her home country the next day. The patient was started on anticoagulant therapy (bemiparin sodium 5000 IU 1x1 subcutaneously) to provide thromboembolism prophylaxis and she was informed that an operation was necessary. The patient was discharged with no additional problems.
Correspondence: Seyhan Y1lmaz, Department of CardioVascular Surgery, Özel Giresun ADA Hospital, Giresun, Turkey.

Tel.: +90.5320674178.

E-mail: drseyhanyilmaz61@gmail.com

Key words: Saphenous vein; venous aneurysm; Doppler ultrasound.

Contributions: SY, idea and article writing; SZ, critical evaluation; FK, FG, article review and references review from the literature.

Conflict of interest: the authors declare no conflict of interest.

Received for publication: 21 May 2019

Revision received: 20 August 2019.

Accepted for publication: 20 August 2019.

This work is licensed under a Creative Commons Attribution 4.0 License (by-nc 4.0).

OCopyright: the Author(s), 2019

Licensee PAGEPress, Italy

Veins and Lymphatics 2019; 8:8298

doi:10.4081/vl.2019.8298

\section{Discussion and Conclusions}

Venous aneurysms, which are described in different publications in the literature as the dilation of the adjacent venous segment more than 1.5 times or dilatation of the diameter of the adjacent venous segment 3 times or the dilatation of the diameter of the adjacent venous segment 2 times, are rare clinical pathologies. ${ }^{5,6}$ They can be observed in different segments of the venous system such as axillary, popliteal, femoral, iliac or greater saphenous vein aneurysms.

As in our case, greater saphenous vein aneurysms, which can be easily diagnosed by color Doppler ultrasound examination and can be differentiated from other clinical pathologies, can be easily confused with inguinal hernias or soft tissue masses during physical examination. ${ }^{3,4}$

The most common symptoms of greater saphenous vein aneurysms are swelling in the groin, pain and edema, and they are morphologically divided into two groups as fusiform or saccular. In addition, according to their location in the saphenous vein system, they are classified under four groups by Pascarella et al. ${ }^{5,7}$ According to this classification, our case was of Type I-fusiform aneurysm where $1 / 3$ proximal greater saphenous vein was involved.

Although the causes of venous aneurysms are not clear, it has been reported that they may develop due to trauma, 
inflammation and degenerative changes, mostly due to congenital or connective tissue diseases. ${ }^{1,5}$ In addition, it has been reported that the etiology of venous aneurysms that can form secondary to chronic venous diseases are persistent venous hypertensions and valvular dysfunctions, as is the case in varicose segments. ${ }^{6}$ In the history of our patient who has reported that her current complaints had been present for almost three years and did not diminish, there were no reports of degenerative or connective tissue diseases, inflammatory diseases and trauma venous doppler ultrasonographic examination revealed, a $70 \times 31 \mathrm{~mm}$ sized fusiform proximal greater saphenous vein aneurysm and grade-4 pathologic reflux in the right saphenofemoral junction.

Doppler ultrasonography and venography can be used in the diagnosis of venous aneurysms and venography is inadequate in the presence of thrombus in the aneurysm sac. The venous Doppler ultrasonography used in the diagnosis and evaluation of our patient is a more effective auxiliary diagnostic tool in the evaluation of the presence of thrombus and the diameter of the aneurysm, compared to the venography. ${ }^{7}$

Due to the fact that the increment in venous diameter increases the possibility of stasis development, the presence of aneurysm increases the risk of potential thromboembolism depending on the venous system it develops. Although it has been reported that aneurysms in the popliteal vein, axillary vein and greater saphenous vein may coexist with venous thromboembolism complications and the majority of pulmonary emboli are caused by the deep venous system (usually by the popliteal vein) compared to the superficial venous system, it has been reported in the literature that thrombus in the greater saphenous vein aneurysm sac may cause a serious complication such as pulmonary embolism. ${ }^{6-9}$ The thrombus in the aneurysm sac could not be detected in our patient and in the physical examination of our patient, neurological deficits were not observed. However, it must be considered by the physician that the pain complaint may be caused by neuropathy. ${ }^{\text {? }}$

Due to the high risk of thromboembolism, surgical treatment is preferred in venous aneurysms and the location and type of aneurysm is important in the surgical approach. ${ }^{10}$ Surgical options according to the location and type of aneurysm include ligation, simple resection, end-to-end anastomosis, resection and vein graft or polytetrafluoroethylene graft interposition,

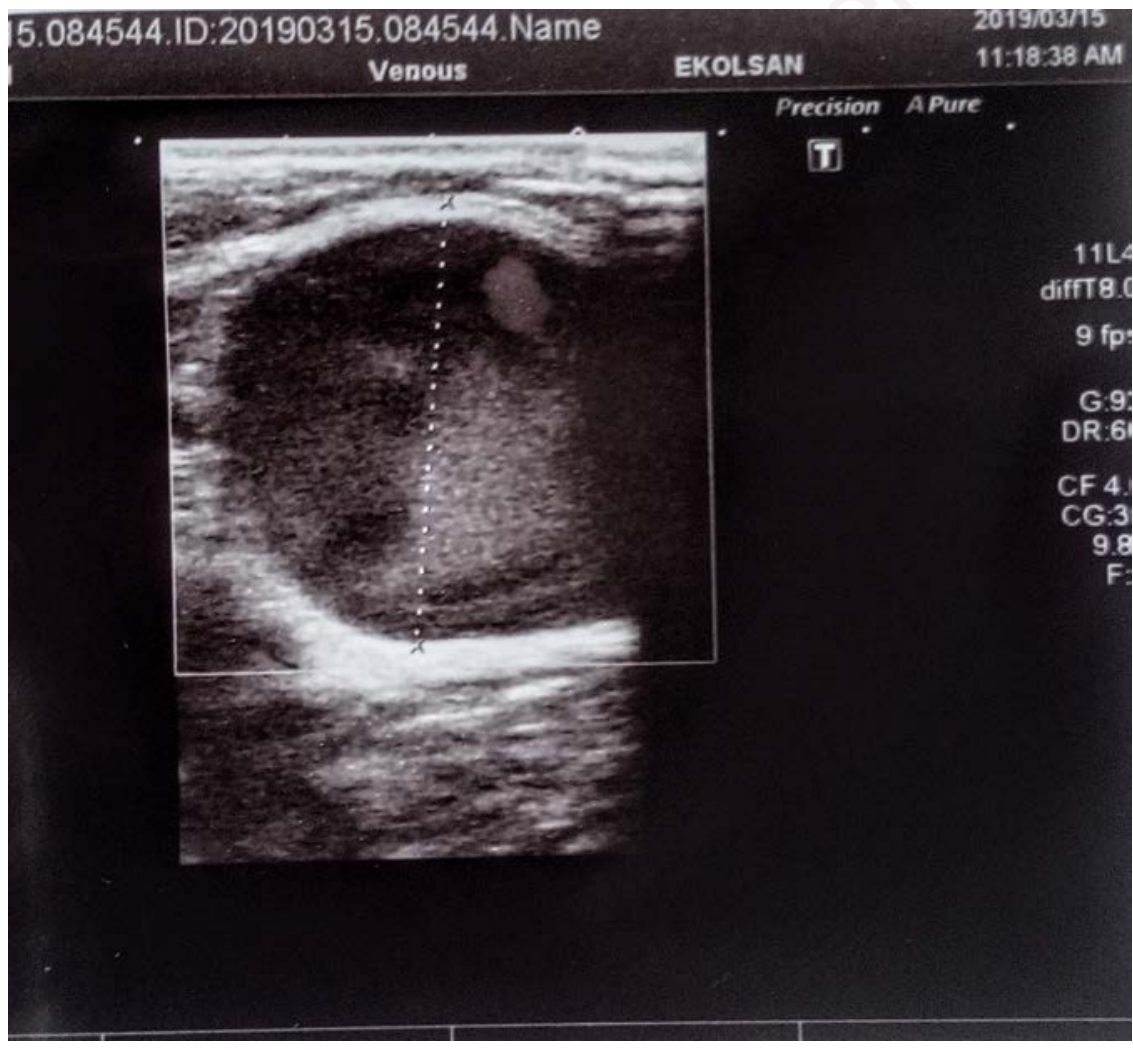

Figure 1. The ultrasonography scan shows a $70 \times 31 \mathrm{~mm}$ diameter fusiform aneurysm of greater saphenous vein. aneurysmalaphy or tangential excision, and lateral venoraphy. ${ }^{11}$ Preserving the saphenous veins with normal distal structure-segments is important in terms of using them as conduits in peripheral or coronary bypass surgeries, which may be necessary in the future, and the repair of greater saphenous vein aneurysm should be the most preferred surgical method. ${ }^{1,11,12}$ Although they are alternative treatment methods for the treatment of greater saphenous vein aneurysms, endovenous thermal ablation and endovenous pharmacological obliteration applications are generally not preferred due to the size and location of the aneurysm. ${ }^{7}$ Since our patient refused the operation because she had to return to her home country the next day, she was started on low-molecularweight heparin (bemiparine sodium 5000 IU $1 \times 1$, subcutaneously) treatment to provide preoperative thromboembolism prophylaxis and discharged from the hospital.

As a result, the swelling detected in the inguinal region should be evaluated in terms of possible superficial venous aneurysm, which may cause thromboembolism and ruptures, and this condition, which is frequently confused with inguinal hernia or soft tissue masses, should be taken into consideration and taken under operation as soon as possible in case of its presence.

\section{References}

1. Majeski J. Surgical repair of primary saphenous vein aneurysm of the proximal leg after initial presentation as an inguinal hernia. Am Surg 2002;68:9991002.

2. Ekim H, Kutay V, Tuncer M, et al. Management of primary venous aneurysms. Saudi Med J 2004;25:303-7.

3. Reggina G, Rizzo S, Impedova G. Aneurysm of external jugular vein: case report and review of literatureea case report. Angiology 1992;108:92-5.

4. Gillespie DL, Leonel Villavicencio J, Gallagher C, et al. Presentation and management of venous aneurysms. J Vasc Surg 1997;26:845-52.

5. Pascarella L, Al-Tuwaijri, Bergan JJ, et al. Lower extremity superficial venous aneurysms. Ann Vasc Surg 2005;19:6973.

6. Bush RG, Bush P. Aneurysms of the superficial venous system: classification and treatment. Veins and Lymphatics 2014;3:4503.

7. Simsek E, Bugra O. Great saphenous vein aneurysm presenting as an inguinal hernia. Asian J Surg 2014;37:208-10. 
8. Owen TD. Thrombosed sapheno-varix: an important and unusual differential diagnosis of strangulated femoral hernia. Br J Clin Pract 1990;44:754.

9. Gianesini S, Menegatti E, Zuolo M, et al. Spontaneous thrombosis of primary external jugular veins aneurysms. Veins and Lymphatics 2013;2:e17.

10. Schatz IJ, Fine G. Venous aneurysms. N
Engl J Med 1962;266:1310-2.

11. Marcucci G, Accrocca F, Antignani PL, et al. An isolated aneurysm of the thigh anterolateral branch of the greater saphenous vein in a young patient presenting as an inguinal hernia. Interact Cardiovasc Thorac Surg 2010;10:6545.

12. Ranero-Jua'rez GA, Sa'nchez-Go'mez
RH, Loza-Jalil SE, et al. Venous aneurysms of the extremities: report of 4 cases and review of literature. Angiology 2005;56:475-81.

Ranero-Jua'rez GA, Sa'nchez-Go'mez RH, Loza-Jalil SE, et al. Venous aneurysms of the extremities: report of 4 cases and review of literature. Angiology 2005;56:475-81. 